\title{
Perspective of hidden curriculum in police college English course the cultivation of thinking path
}

\author{
Zhe Sun \\ Xinjiang Police College Language Department Xinjiang Urumchi, 830011
}

\begin{abstract}
Keywords: thinking; Hidden curriculum; The public security colleges and universities; College English course
\end{abstract}

\begin{abstract}
English courses, students lack of initiative in English learning, lack of deep thinking in English ability, the public security colleges and universities students absent "dialectic" phenomenon is widespread. In this paper, according to the characteristics of the students in police colleges from the Angle of view of the hidden curriculum, through the experimental study confirmed that the possibility of police colleges students' English ability training. Introducing the cultivation of the ability in the "hidden curriculum", through the hidden curriculum design and practice, discuss public security universities and colleges speculative paths of cultivating the ability of college English course.
\end{abstract}

\section{Introduction}

"Thinking" originated in the sixties and seventies of the last century, is refers to the individual in determining the true value of things in the process, using the appropriate evaluation criteria, conscious thought, finally make a rational according to the ability of judgment. Professor [1] g. thinking made relatively comprehensive definition: thinking is the thinking and analysis, it is a kind of phenomenon through things analysis and reasoning, logic and make a rational choice, including thought, this paper, analysis and problem solving skills. It is a cognitive, analysis, interpretation, evaluation, reasoning, interpretation, self-regulation) and personality traits (curious, open, honest, confident, insist on). [2], in thinking theory research at home and abroad are more influential include "Delphi" project team double d structure model, Richard Paul ternary structure model and the hierarchy of g. theory model and chong-de Lin triangular structure model.

In the national medium and long-term education reform and development plan outline (2010-2020) ", to improve the ability of college students, learning ability, practice ability and innovation ability. The cultivation of thinking ability is the important indicators of talents cultivation in colleges and universities. Visible, in the current quality education system in our country, for the cultivation of the ability to become an important content. Along with the development of The Times and social progress, with simple language skills English courses have already can't adapt to the requirements of the current, instead should improve language basis, broaden the students knowledge, improve students' cultural consciousness, thinking and judging ability of college English course. Through literature review, found that the domestic ability of study mainly for English major students, through the theoretical and empirical study English major student ability raise, the effective ways for other professional or few students study English level is not high.

Through the discussion of teacher and found that the public security colleges and universities teachers is generally believed that students' English level is not high, in xinjiang police academy, for 
example, in the undergraduate class, ethnic minority students accounted for a third of the total number of zero beginnings, although these students in high school have an English class, but English is not final exam, college entrance examination English do not ask, because there is no test pressure, students will naturally give up this course, so this part of the students entered the university English is zero basis, but after entering the university, they are not being a placement or hierarchical teaching; Second, about one-third of the students' English foundation is weak, the college entrance examination scores less than half; And one third of the students has a strong interest in learning English, English foundation is good, study enthusiasm high, but it is difficult to transfer the other students. Therefore, the teachers think that teaching is focus on playing good language foundation, cultivate students' ability of teaching target is very difficult to achieve.

\section{The public security colleges and universities the hidden curriculum in college English course}

Records dating back to Plato period of hidden curriculum. At the beginning of last century, American educator John Dewey put forward the concept of "incidental learning", "pointed out that in the specific content of the learning process, the formation of emotion and attitude towards learning content and learning process, such as like or dislike emotion and so on." [3] the United States education sociologist, flexor done in-depth research on emotional value of the process of learning, he thinks a neatly divided into "primary learning" of learning, "deputy learning" and "learning" attached three parts. The main learning refers to the directly obtained in the process of learning knowledge and skills. Vice learning refers to the Lord in the learning process, relevant knowledge and skills involved; Attached refers to the learning culture in the course of ideal moral habits, attitudes, and emotional quality. "Incidental learning" and "learning" the concept of the two for the hidden curriculum concept of laid a foundation.

The concept of "recessive course" is published by the American educator and theorists IN 1968, Jackson's book "the class LIFE" (LIFE IN CLASSROOM), he thought the "hidden curriculum is every teachers and students are the key to success IN the university," [4] it is, as opposed to a dominant curriculum is dominant curriculum IN the school education is "planned and organized to the implementation of the formal curriculum" [5], hidden curriculum is "students IN the learning environment, learned than expected or is planning of knowledge, values, norms and attitudes." [6] both in every pedagogue in the process of development and growth are necessary, they complement each other, mutual penetration, mutual transformation, effective in promoting learning. Our education scholars to delve into the hidden curriculum, notice the hidden curriculum can maximize the function and effect of education, lets the student in imperceptible acquisition, through the hidden curriculum design and organization, exert its positive and positive function, avoid negative factors.

Public security colleges and universities of college English "dominant curriculum" refers to in order to improve the students' language skills for the teaching goal of college English curriculum, teaching content including listening, reading, speaking, writing and translating several input and output link, the teaching emphasis on language points and the interpretation of knowledge and the training of language skills. Hidden curriculum refers to the students in the process of language learning, the cultivation of their value, the language specification and standard language consciousness. In dominant curriculum and hidden curriculum supplement each other, under the penetration of specification constantly learning habits, and gradually form their own learning style, set up suitable for individual learning strategies, in the process of learning, through the internalization, the conversion of tacit knowledge to explicit knowledge, eventually form a system of explicit knowledge, improve the learning effect. 
The first phase of the formation of speculative ability in vocabulary learning vocabulary is the foundation of language learning, occupies a large proportion in learning English. Most of the public security colleges and universities student accustomed to passive learning ways of high school, they habitually expect the teacher to tell them what are the key words, again by the teacher, for example to explain. If you meet new words,Students usually use mobile phone dictionary to refer to a simple word to understand the meaning, ignore word pronunciation, the part of speech, the use of context, phrase collocation, etc., in the long term, the students in the process of language input, there is no dictionary can't read articles, in the language output, the word misuses of everywhere. Therefore, in the hidden curriculum, pay attention to cultivate the standardization of the language learning. "College experiencing English integrated course of every unit around a center, so the author in the experimental classes require students to refer to the new words in the text before the class, and are summarized and classified. Find out the new words and topics related vocabulary, students also can be added. In addition, classifying words, classification standard can be according to the parts of speech, scenario, etc. Class, the students first please show, share the results. Then the teacher check the key words in the text in the form of questions, including pronunciation, collocation, use context, in this way, students find what is missing, in the process of self-study in vocabulary learning in the future to be able to continuously develop effective methods of vocabulary acquisition. In order to consolidate the usage of the new words and match, in the second class, to ask students to retell the article content in the form of fill in the blanks, focuses on whether students master these words. Obvious curriculum and hidden curriculum supplement each other, prompted the students' effective in vocabulary acquisition.

The second stage Actively build text decoding and construct "four levels of learning identity model" theory is intensive reading course is an important theoretical basis for the cultivation of students' thinking ability, it deeply explained the learners to interact with the text in the four layers. Decoding the text, to decode the text in the daily life; Builders, the significance of text interpretation and inference, the construction of meaning; Users of the text, understand the style of the text, purpose, structure, etc., the text social and cultural functions in the practical life; Text analysis, to critical analysis and thinking of the text, understand their point of view, position and orientation. [7] in hidden curriculum design, training students the sentence patterns and structure analysis of consciousness. In the experiments, the security of the class using traditional teaching methods, teachers of sentence patterns and structure were analyzed, and the results show that the students in learning new lessons, and don't realize that the reason for the article content understanding deviation due to the structure of the article and sentences lack of analytical ability. In prison science class, the teacher asked the students according to the title of the text and pictures for thesis writing, students are required to use of new words in the text, also is the last class of language points, at the same time pay attention to the continuity of the article. Dominant curriculum now let students consciously use words, from input to output process. Found in students language output, the writing is not just the words and sentences, and also need to have the article structure and syntax of thinking, and this is what they lack. Through writing hidden curriculum design, students in learning the new text will consciously to explore the characteristics and function structure, sentence patterns, students are encouraged to question when reading articles. After learning the text, guides the student to discuss how the article topic to write, refactoring text, compared with the original text, analysis their respective advantages and disadvantages. Before writing, teachers can give students writing skills of knowledge. By decoding the text and build, encourage students to think deeply about the text.

The third stage The contents of the article deeply analyzes the cultivation of reading ability to 
layered, according to the degree of difficulty, can be divided into memory, understanding and thinking. Under the guidance of teachers and students to read the article has carried on the cognitive level, through the analysis of language points, sentences and paragraphs, students understand the content of the article. And in the process of foreign language learning, students tend to be expressed by the target language without thinking views and attitudes of acceptance, the lack of deep thinking. In hidden curriculum design, should consider how to arouse the students, the author's writing intention to explore the value of the article, consciousness, and to identify and appreciate the article, even questioned, form their own judgments. Students could be grouped, teachers guide students to consult and relevant cultural background information, requests the student to the author's writing intention and the value of the article design problems, change the previous teachers ask students to answer mode, under the guidance of teachers, the students to ask questions, student to answer. On the one hand, students must have a deep understanding of the content of the article also must carry on the deep reading, as well as the related information, on the other hand, students are in the reading on the basis of analysis, inference and evaluation, under the design of the hidden curriculum, cultivate the students for the exotic culture under the background of the article the depth of thinking.

\section{Conclusion}

As a kind of thinking habits, training in public security colleges and universities students thinking is feasible, effective use of the carrier of college English course, through the hidden curriculum to the dominant curriculum transformation to realize the cultivation of ability, not only improve the students for the sensitivity of the language, standardize the habit of the students' language learning, to enhance the students' ability for the analysis of the problems, and improve the students' self-study ability, these are the important part of quality education.

\section{Acknowledgement}

Fund project: autonomous region in 2014 young teachers in colleges and universities to cultivate scientific research projects "based on the teaching experience of the public security colleges and universities in xinjiang college English intensive reading teaching design reform research" (approval number: XJED2014S078)

\section{Reference}

[1] Shi Guangxiao. Foreign language of hidden curriculum review and thinking [J]. Foreign language audiovisual education, 2010, (5).

[2] Su Jing. Theory of the status quo and development of college English teaching of police way [J]. Journal of education culture. 2009, (2).

[3] stone belle. Theory of public security professional characteristics of foreign language teaching [J]. Journal of vocational technology, 2006. (4) : 54.

[4] Wang Xinxi LiHui. Development and utilization of hidden curriculum of college English teaching [J]. Journal of success (education), 2012, (5).

[5] g. Wang Jianqing etc. Students of construction of China's foreign language ability of measuring theory [J]. Foreign language world, 2009, (01). 
[6] zhang jz. "hidden curriculum" and controllable factors of study [J]. Journal of northwestern polytechnical university, 2012, (12).

[7], g. Wang Jianqing Zhao Cairan, Liu Yanping, Wang Haimei. The speculative tendencies measuring tool reliability research of university students in China [J]. Foreign language audiovisual education, 2011 (6).

Author: Zhe Sun (1980-), female, Xinjiang Urumqi, lecturer of Language Department of Xinjiang P olice College, master of English language and literature, mainly engaged in the study of English La nguage Teaching 